\title{
AVALIAÇÃO DE UMA TRAJETÓRIA: TECNOLOGIAS SOCIAIS TRANSFORMANDO RURALIDADES NO SEMIÁRIDO BAIANO
}

\author{
João Paulo dos Santos Silva1; Alessandra Alexandre Freixo2 \\ 1. Bolsista PROBIC/UEFS, Graduado em Ciências Biológicas, Universidade Estadual de Feira de Santana, e-mail: \\ jpss.bio@gmail.com \\ 2. Orientadora, Departamento de Educação, Universidade Estadual de Feira de Santana, e-mail: aafreixo@ hotmail.com
}

PALAVRAS-CHAVE: Educação do Campo; Juventude Rural; Tecnologia Social.

\section{INTRODUÇÃO}

Vivemos em uma época em que as tecnologias, mais do que nunca, fazem parte do nosso cotidiano. Dentre essas tecnologias, observa-se um destaque relevante para a internet, a televisão, as mídias digitais, os celulares, entre tantas outras. Por outro lado, existe outro viés tecnológico tão importante que tem ganhado espaço cada vez mais considerável em muitas comunidades, cidades e regiões do Brasil, conhecido como tecnologia social (TS). Apesar das tecnologias sociais estarem voltadas para pequenas empresas, cooperativas e pequenos agronegócios, elas estão começando a ser desenvolvidas sob outros olhares e experiências em universidades e escolas.

Neste sentido, destacam-se as experiências de Lopes e colaboradores (2011) e Bagattolli e Jesus (2013), ambas buscando o desenvolvimento de TS com cunho pedagógico. Ao longo dos anos, o conceito sofreu modificações e adequações para a concretização de uma política pública sob a concepção geral de uma participação comunitária no processo de construção tecnológica, um custo baixo de investimento e do produto dessa construção, bem como a simplicidade e os aspectos positivos oriundos de sua aplicabilidade em um determinado lugar (DAGNINO et al., 2004).

De acordo com Thomas (2009), TS é uma maneira de criar, desenvolver, implementar e administrar tecnologia orientada a resolver problemas sociais e ambientais, gerando dinâmicas sociais e econômicas de inclusão social e de desenvolvimento sustentável. Neste sentido, este trabalho tem como objetivo analisar uma tecnologia social que vem sendo desenvolvida no contexto da Educação do Campo no semiárido baiano, e como essa TS tem contrubuído para a construção de novas ruralidades.

\section{METODOLOGIA}

No ano de 2012, como fruto de um rico momento de vivências advindas do estágio supervisionado desenvolvido na EFA de Valente, inicia-se a construção da Tecnologia Social, o I CCT. Aliado ao diálogo entre sujeitos, foram realizadas observações na EFA-Valente em diferentes períodos de alternância, seguindo o viés reflexivo da metodologia da pesquisa-ação participante proposta por Barbier (1985). As observações do cotidiano escolar foram importantes para uma melhor compreensão e identificação dos diferentes instrumentos pedagógicos que caracterizam a proposta de alternância da escola. Os diálogos que ocorreram durante todo o processo serviram de fonte para um exercício de encontro de complexidades rumo à construção e significação de uma nova experiência. Dentro das atividades desenvolvidas na escola, surgiu uma primeira noção, ainda não claramente definida como tecnologia social, mas que, com a participação da equipe da escola, já envolvida em projetos de pesquisa e extensão em andamento, a atividade finda a se configurar como tal.

A partir dela que os estagiários da universidade, buscando também ampliar seus conhecimentos e contribuir mais amplamente na formação daqueles sujeitos do campo, se engajaram no projeto de extensão e consolidaram o evento como tecnologia social. A construção do Circuito envolveu uma análise documental do projeto político-pedagógico da 
EFA-Valente (2011), como fonte para a observação do processo de maturação ou de evolução dos indivíduos, grupos, conceitos, conhecimentos, comportamentos, mentalidades, práticas, etc. (CELLARD, 2008). Portanto, buscou-se compreender o papel da instituição na formação dos jovens e dos instrumentos avaliativos desenvolvidos pela escola que versam sobre os aspectos socioculturais da região sisaleira, a reflexão desses jovens em suas comunidades, a apropriação das tecnologias no cotidiano, etc. Vale ressaltar o papel de algumas leituras norteadoras no processo de direcionamento dos diálogos e da construção do I CCT, com destaque para Arroyo (2009), Baptista (2003), Dagnino (2009) e Teixeira e Freixo (2011). Assim, todo o embasamento teórico foi importante para determinados encaminhamentos decorrentes dos encontros e diálogos na EFA-Valente e na UEFS.

Após o levantamento de informações foram realizados encontros quinzenais que se intensificaram ao caminho da proximidade do evento. Em alguns encontros, a equipe pedagógica da EFA estava presente; e em outros momentos a equipe se fazia presente através dos contatos pelas mídias sociais. Neste aspecto, as mídias sociais foram uma importante fonte de articulação aberta entre a equipe da escola e da universidade no processo de construção dessa TS, como importantes ferramentas que oportunizaram uma participação ativa em todas as fases de construção do evento, o que confere aos sujeitos uma experiência que se deslocaliza, sem desenraizar-se, no sentido em que os participantes aproximam-se, encurtam as distâncias, sem perder o foco do universo formativo em questão: a construção de uma tecnologia social articulada à educação do campo, ampliando os significados que os sujeitos conferem ao rural e ao campo. Nestes encontros foram discutidas propostas de intervenção que melhor atendessem as demandas daquela experiência para a construção de uma TS adequada e adaptada ao espaço ao qual se planejava desenvolver. Então, viabilizou-se a identificação e descrição das características comuns à diversidade e complexidade de demandas apresentadas dentro da dimensão da EFA-Valente.

\section{RESULTADOS E DISCUSSÕES}

O IV CCT marca um processo de amadurecimento de uma trajetória. Apesar de manter a mesma base de objetivos e perspectivas, o IV CCT culmina de experiências acumuladas ao longo das três edições anteriores. Neste sentido, novas leituras e novos sujeitos marcam esse processo, demonstrando a fluidez e a dinâmica que envolve a TS. Em uma oficina desenvolvida durante as semanas de alternância na EFA Valente, envolvendo a produção de um vídeo-documentário sobre o IV CCT, foram realizadas entrevistas com alguns envolvidos na dinâmica do evento. Outra estratégia utilizada para a compreensão do papel do evento constou de questionários direcionados aos colaboradores do evento e aos estudantes da EFA. Estas ferramentas de investigação contribuíram para uma análise do papel do evento a partir de alguns aspectos experienciais dos sujeitos envolvidos.

No caminho de análise dessas narrativas é possível perceber uma diversidade de significações sobre o Circuito. A partir delas buscou-se extrair elementos para identificar e compreender melhor o IV CCT, e muitas vezes a trajetória de quatro anos de evento. A ideia de compartilhamento de conhecimentos é presente nas narrativas, pois todos os envolvidos no evento se envolveram na dinâmica. O processo experiencial dos sujeitos está interligado pela troca se saberes, vivências e percepções do lugar. Desta forma, seguindo a perspectiva de Bondia (2002), o ato da experiência toca os sujeitos. Portanto, esta experiência não está somente relacionada às oficinas ou exposições, mas pela receptividade e disponibilidade dos sujeitos para uma abertura para o diferente, para o outro. 
"Numa visão particular, acredito que o CCT é um espaço de encontro com a diversidade e compartilhamentos de saberes" (Dalilal, oficineira, Licencianda em Biologia).

"Sempre aprendi com os estudantes, moldando minhas próprias práticas e fiquei todas as vezes muito grato em levar novidades e conhecimentos para eles" (Felipe, oficineiro, Biólogo).

Portanto, o evento cria possibilidades de encontro com o diferente, com o inusitado, com a novidade. Por outro lado, a existência de um momento como o CCT cria vínculos da semelhança de um espaço comum, culminando em uma congruência de experiências individuais e coletivas. Este fator é uma das consequências dos diálogos constantes entre a Escola Família Agrícola e Universidade. A intensificação das parcerias e fortalecimento do vínculo entre as instituições ao longo dos anos permitiu uma melhor fluidez na preparação do evento, na montagem das exposições, oficinas temáticas e demais atividades.

"As oficinas foram ótimas, adorei, foram várias atrações, coisas novas, porque em três anos de CCT que já tive, coisas novas são trazidas a cada ano, então é sempre uma nova experiência. O CCT é um novo aprendizado, não tanto pra mim, quanto pra eles [oficineiros], cada vez que eles trazem novas coisas nós ensinamos a eles assim como eles ensinam pra nós, então isso vai criando aprendizados novos, coisas novas, de outras culturas e internas" (Maria Vitória, Aluna da EFA Valente)

A equipe pedagógica da escola já tem o CCT em seu calendário escolar, já discute a TS na jornada pedagógica, e usa-o como ferramenta de ensino-aprendizagem no processo formativo dos estudantes. Este fator é fundamental, pois a identificação do evento como parte da identidade escolar oportuniza diferentes debates, múltiplas propostas e sugestões que estejam em constante diálogo entre EFA e Universidade.

"O CCT é uma iniciativa importante que vem fazendo, na sua quarta etapa, e pra EFA é sempre um prazer receber, porque é uma oportunidade de envolver as turmas e debater temáticas diferentes do que a gente acaba tratando aqui na EFA, além das temáticas serem voltadas para fortaceler o que a gente estuda aqui na EFA" (Messias, diretor da EFA Valente).

Em toda a trajetória do Circuito evidenciou-se a relação social entre os sujeitos e as temáticas trabalhadas, integrando o conhecimento popular ao científico, as tecnologias e a cultura, discutindo demandas que a escola, os estudantes e a comunidade convivem. Assim, a construção e materialização de tecnologias sociais de pertencimento ao lugar envolvendo a comunidade escolar foram fundamentais para o desenvolvimento de uma identidade como sujeitos individuais e coletivos, seja por meio de propostas de produção coletiva de textos, hipertextos ou vídeo-documentários, no intuito do resgate aos sentidos e às trajetórias vividas pelos envolvidos com a EFA-Valente, como suporte ao debate sobre as potencialidades da educação do campo proporcionada pela instituição.

\footnotetext{
${ }^{1}$ Todos os nomes presentes nos depoimentos são reais, por reconhecer que o trabalho do Circuito de Ciência, Cultura e Tecnologia é de natureza coletiva, logo a autoria da tecnologia é compartilhada, num trabalho colaborativo com a escola. A troca dos nomes dos colaboradores retira deles a autoria de parceiros, de sujeitos da ação.
} 


\section{CONSIDERAÇÕES FINAIS}

As tecnologias sociais são importantes alternativas para o desenvolvimento de iniciativas e projetos voltados para situações e comunidades específicas. Para além das pequenas empresas, cooperativas e pequenos agronegócios, as TS podem estar sendo desenvolvidas sob a perspectiva pedagógica. Em vista disso, uma TS de cunho pedagógico pode apresentar uma variedade de iniciativas, e uma amplitude de resultados inimagináveis. $\mathrm{O}$ Circuito de Ciência, Cultura e Tecnologia é apenas uma das possibilidades de aplicação de uma TS sob esse viés. Apesar dos desafios encontrados durante a trajetória dos Circuitos, a constatação de que aquela TS está se desenvolvendo, e caminhando com as próprias pernas, tem demonstrado que um espaço escolar aberto, uma equipe pedagógica disposta a discutir ideias, e um alunado disposto a encarar desafios são pontos de uma tríade que constitui um solo fecundo para o desenvolvimento de uma TS. O objetivo deste trabalho não foi chegar a uma conclusão sobre esta trajetória, mas compartilhar esta experiência, tornando-a uma possibilidade a ser desenvolvida em outras realidades, com outras problemáticas, sob outra perspectiva.

\section{REFERÊNCIAS}

ARROYO, M. G. Imagens Quebradas: trajetórias e tempos de alunos e mestres. $5^{\mathrm{a}}$ ed. Petrópolis, RJ: Vozes, 2009.

BAGATTOLLI, C.; DE JESUS, V. B. Educação contextualizada e tecnologia social: a experiência da Casa Familiar Rural de Igrapiúna (BA). In: COSTA, A.B (Org.) Tecnologia Social e Políticas Públicas. São Paulo: Instituto Polis; Brasilia: FBB, 2013, p. 113-132.

BAPTISTA, F. M. C. Educação rural: das experiências à política pública. Brasília: NEAD/Editorial Abaré, 2003. (Série Debates e Ação, 2).

BARBIER, R. A pesquisa-ação na instituição educativa. Rio de Janeiro: Jorge Zahar, 1985. BONDIA, J.L. Notas sobre a experiência e o saber da experiência. Rev. Bras. Educ. n. 19, p. 20-28. 2002. Disponível em: <http://dx.doi.org/10.1590/S1413-24782002000100003>. Acesso em: 26. Mai. 2016.

CELLARD, A. A análise documental. In: POUPART, J. et al. A pesquisa qualitativa: enfoques epistemológicos e metodológicos. Petrópolis: Vozes, 2008. p. 295-316.

DAGNINO, R. P; BRANDÃO, F. C.; NOVAES, H. T. Sobre o marco analítico conceitual da tecnologia social. In: LASSANCE JR. Et al., (Org.). Tecnologia social: uma estratégia para o desenvolvimento. Rio de Janeiro: Fundação Banco do Brasil, 2004. Disponível em: < https://scholar.googleusercontent.com/scholar?q=cache:3qQhcv4g44UJ:scholar.google.com/ \&hl=pt-BR\&as_sdt=0,5>. Acesso em 13. Abr. 2016.

EFA VALENTE. Projeto Político Pedagógico. 2011. Mimeo.

LOPES, R. E; BORBA, P. L.O.; TRAJBER, N.K.A.; SILVA, C. R.; CUEL, B. T. Oficinas de atividades com jovens da escola pública: tecnologias sociais entre educação e terapia ocupacional. Interface. v.15, n.36, p. 277-288, 2011. Disponível em: <http://dx.doi.org/10.1590/S1414-32832011000100021>. Visualizado em: 13 Abr 2016.

TEIXEIRA, A. M. F.; FREIXO, A. A. Educação do campo e memória de velhos: navegando entre o passado e o presente. Revista Contrapontos, v.11, n.1, p. 14-23. 2011. ISSN 19847114. Disponível em: <http://siaiap32.univali.br/seer/index.php/rc/article/view/2261>. Acesso em: 14. Abr. 2016.

THOMAS, H. E. Tecnologia para inclusão social e políticas públicas na América Latina: In: OTTERLOO, A. (Org.). Tecnologias Sociais: Caminhos para a sustentabilidade. Brasília: Rede de Tecnologia Social, 2009, pp. 25-82. 